\title{
O PAPEL DO ENGENHEIRO QUÍMICO NO MERCADO DE TRABALHO: PRODUÇÃO DE UM GUIA PRÁTICO DIGITAL DESTINADO AOS GRADUANDOS E DEMAIS INTERESSADOS NA PROFISSÃO
}

\author{
PEREIRA, Raphael Carlos Rosa ${ }^{1}$ e SILVA, Eder Dias da. ${ }^{2}$ \\ ${ }^{1}$ Graduando em Engenharia Química, Centro Universitário de Patos de Minas \\ ${ }^{2}$ Mestre em Ensino de Física (PUC Minas), Centro Universitário de Patos de Minas \\ E-mail para contato: contatoraphaelpereira@gmail.com
}

\begin{abstract}
RESUMO - Ao ingressar no curso de engenharia química, o aluno por vezes apenas tem afinidade pelas matérias relacionadas ao curso, mas não conhece o mercado de trabalho da profissão. Nesse sentido, foi realizado um questionário aos alunos do curso de engenharia química do Centro Universitário de Patos de Minas, para saber se conheciam toda área de atuação do engenheiro e como os alunos se sentem em relação a como a instituição lhes apresenta informações sobre o mercado. Constatou-se que os alunos não estão completamente satisfeitos com a forma com que lhes é apresentado o mercado. Propôs-se então a criação de um guia para os graduandos no qual encontrariam conteúdos como áreas de atuação e as novas exigências das empresas, sendo aprovado por $92 \%$ dos alunos e $87 \%$ dos professores. Portanto, foi produzido um livro digital, disponibilizado gratuitamente, para que os alunos tenham maior conhecimento das oportunidades que terão quando formados.
\end{abstract}

\section{INTRODUÇÃO}

Todo profissional tem como objetivo aplicar seus conhecimentos aprendidos na vida acadêmica em processos práticos, a fim de que seu trabalho possa melhorar a qualidade de vida de toda a população. De acordo com o Departamento de Engenharia Química da Universidade Federal do Rio Grande do Sul, a atuação do engenheiro químico é fundamental em todas as etapas, de pesquisa e desenvolvimento de novos produtos e na concepção de indústrias, bem como na operação e otimização do processo produtivo.

No geral, todas as engenharias contam com uma grade curricular semelhante nos primeiros períodos de curso, abrangendo áreas da matemática, física e química. Além das disciplinas básicas, o engenheiro químico precisa dominar áreas específicas para aplicar seus conhecimentos na indústria química.

No entanto, esse profissional não pode mais se limitar aos conhecimentos adquiridos no ensino superior, visto que o cenário atual da sociedade é de constantes mudanças provocadas pelo surgimento de novas tecnologias.

De acordo com Werthein (2000), as transformações em direção à tecnologia da informação e à flexibilidade de informações e modos de trabalho estão ganhando força não só 
nos países industrializados, como também em nações menos desenvolvidas. Dessa forma, vivemos na chamada "sociedade da informação" ou "sociedade do conhecimento", definições que passaram a substituir o termo de "sociedade pós-industrial".

Portanto, o engenheiro químico deve sempre se atentar às mudanças e na forma de trabalho exigida, nas novas tecnologias, na maior flexibilização de processos industriais e, sobretudo com o mundo globalizado em que há o encurtamento de distâncias e aumento da velocidade do fluxo de informações compartilhado entre as indústrias.

Este projeto tem como objetivo geral identificar qual o papel do engenheiro químico no mercado de trabalho em uma sociedade de constantes mudanças, apresentando o perfil que se espera para o futuro profissional.

Além disso, será confeccionado um guia prático que terá como conteúdo: áreas de atuação do profissional da engenharia química, as exigências do mercado de trabalho globalizado para o futuro engenheiro e a importância do empreendedorismo na profissão, para que os graduandos se orientem no ambiente de trabalho e cheguem mais preparados ao mercado.

O desenvolvimento da pesquisa será de grande relevância para a formação acadêmica dos graduandos do curso de engenharia química do Centro Universitário de Patos de minas, visto que será possível ampliar o conhecimento sobre a atuação do profissional na prática.

A produção do guia prático é uma forma de auxiliar os futuros engenheiros a chegarem mais preparados e confiantes ao mercado de trabalho. Além disso, será possível promover a vontade de se manterem atualizados após a formação, aprendendo a lidar com os novos desenvolvimentos tecnológicos de processos e com as novas ferramentas que surgirem durante a carreira profissional.

\section{REVISÃO DE LITERATURA}

Graças aos novos meios de comunicação e às novas tecnologias que surgiram na modernidade, o mundo está ficando totalmente conectado e globalizado. O cotidiano está sendo marcado por inúmeras mudanças e inovações nas formas de produção e nos modos de trabalho, de maneira que os engenheiros do futuro trabalharão de forma totalmente diferente dos atuais.

De acordo com Zangirolami (2009), a internacionalização da educação em engenharia é fundamental para que os alunos cheguem ao mercado de trabalho com diversas habilidades e com uma visão globalizada.

A formação do engenheiro atualmente passa pela formação acadêmica, programas de estágio e educação continuada. No entanto, apenas a formação acadêmica já não é mais suficiente para atender todas as exigências do mercado de trabalho atual, pois as empresas e mercados estão cada vez mais globalizados, exigindo conhecimento de novos procedimentos de engenharia. 
O profissional da engenharia química pode atuar em vários setores em que ocorrem processos de transformação, como mostra o quadro 1. Em todas estas áreas é fundamental que o engenheiro possua uma visão globalizada, empreendedora e atualizada do processo produtivo.

Quadro 1 - Áreas de atuação do engenheiro químico (CREMASSO, 2005 citado por MELLO, 2013).

\begin{tabular}{|l|l|}
\hline Açúcar e álcool & Papel e Celulose \\
\hline $\begin{array}{l}\text { Borracha sintética e seus produtos e } \\
\text { películas }\end{array}$ & Plásticos e resinas \\
\hline Cosméticos e perfumes & Química \\
\hline Catalisadores & Química fina \\
\hline Fármacos e bioprodutos & Petróleo \\
\hline Fibras sintéticas e têxteis & Petroquímica \\
\hline Gases industriais & Refratários e Cerâmicos \\
\hline Gorduras, óleos & Sabões, detergentes \\
\hline Insumos Químicos & Tintas e vernizes \\
\hline
\end{tabular}

Tendo em vista o papel global e multifuncional do engenheiro na sociedade da informação, Brasil (2013) cita algumas características fundamentais que o engenheiro químico deve possuir:

- habilidade para realizar o trabalho definindo problemas e esquematizando soluções.

- $\quad$ capacidade de trabalhar em equipe e ter boa relação interpessoal para convencer que suas decisões são corretas.

- $\quad$ ter iniciativa e sugerir novas tarefas que vão contribuir para o sucesso da organização

- vontade de se manter atualizado com os novos desenvolvimentos tecnológicos de processos e com as novas ferramentas.

- $\quad$ pesquisar novas técnicas úteis na literatura, em encontros profissionais e entre os colegas mais jovens.

Portanto, estar sempre atualizado e pronto para resolver qualquer problema na empresa em meio ao surgimento das novas tecnologias é o novo desafio para o profissional da engenharia. Entretanto, um dos grandes obstáculos para essa nova era da engenharia, tem sido justamente a falta de profissionais capacitados para enfrentar esse novo desafio, onde se valoriza o engenheiro multiespecialista ${ }^{1}$, ao contrário do especialista. (PÓVOA; BENTO, 2005).

Dessa forma, o mercado de trabalho da "sociedade da informação e do conhecimento" exige profissionais multifuncionais, que tenham uma visão global e rápida adaptação para enfrentar os desafios do comércio e da produção do século XXI.

\footnotetext{
${ }^{1}$ Que é capaz de desempenhar várias funções dentro de seu local de trabalho.
} 


\section{MATERIAIS E MÉTODOS}

A fim de analisar o nível de satisfação dos graduandos do curso de engenharia química do Centro Universitário de Patos de Minas em relação às perspectivas que são apresentadas durante sua formação acadêmica, tanto sobre o mercado de trabalho na prática quanto às habilidades exigidas para o profissional globalizado na sociedade da informação e do conhecimento, foi aplicado um questionário seguindo a metodologia de Hill (2012).

Os alunos foram questionados sobre o conhecimento deles em relação às áreas de atuação do engenheiro químico, a respeito do grau de satisfação em relação a como o curso lhes apresenta o mercado de trabalho, a importância de ser um profissional multifuncional, sobre o empreendedorismo e a atualização constante, nível de domínio da língua estrangeira e a satisfação quanto à criação do guia prático apresentando as áreas de atuação e as exigências do mercado globalizado, baseado na rotina e no mercado de trabalho de engenheiros mais experientes. Além disso, foi elaborado um segundo questionário a ser aplicado aos professores do curso de Engenharia Química a fim de comparar as respostas de acordo com os interesses e perspectivas sobre o mercado de trabalho.

O guia prático proposto neste projeto foi elaborado entre os meses de dezembro de 2016 a março de 2017. Denominado "Guia da Engenharia Química", é um ebook destinado aos graduandos em engenharia química e demais interessados na profissão, composto por exigências do mercado de trabalho em relação ao engenheiro químico, apresentando links de acesso a outras páginas e artigos para aumentar o leque de informações e ser um guia interativo com o leitor.

A fim de facilitar o acesso ao guia prático, foi criada uma página na internet no endereço "www.guiadaengenhariaquimica.com" na qual ele é disponibilizado gratuitamente a quem se interessar.

\section{RESULTADOS E DISCUSSÕES}

Após a aplicação dos questionários em sala de aula, foi realizado um levantamento de dados e em virtude dos dados coletados, foi possível analisar que os graduandos ainda se sentem insatisfeitos com a forma com que o curso os apresenta informações sobre o mercado de trabalho. O guia prático e didático que lhes acrescente informações a respeito das perspectivas do mercado e as exigências das empresas do mundo globalizado será de grande ajuda para aumento significativo do interesse pela profissão.

O papel do engenheiro químico no mercado de trabalho no mundo atual pode ser resumido em alguns pontos principais: ser capaz de trabalhar em equipe e atuar na gestão de pessoas, ter iniciativa e liderança para organizar seu trabalho, atuar de maneira ética e responsável aplicando a capacidade de resolver problemas da maneira mais lucrativa e sustentável, dirigir, supervisionar e executar processos industriais ligados à química, ser comunicativo e se manter atualizado sempre às novas tecnologias que surgirem dentro do ramo. 
A figura 1 mostra a capa do guia prático produzido e a forma de acesso ao conteúdo desse material, de forma totalmente gratuita a todos os graduandos e demais interessados na área.

Figura 1 - Guia Prático Elaborado no Projeto: E-book “Guia da Engenharia Química”.

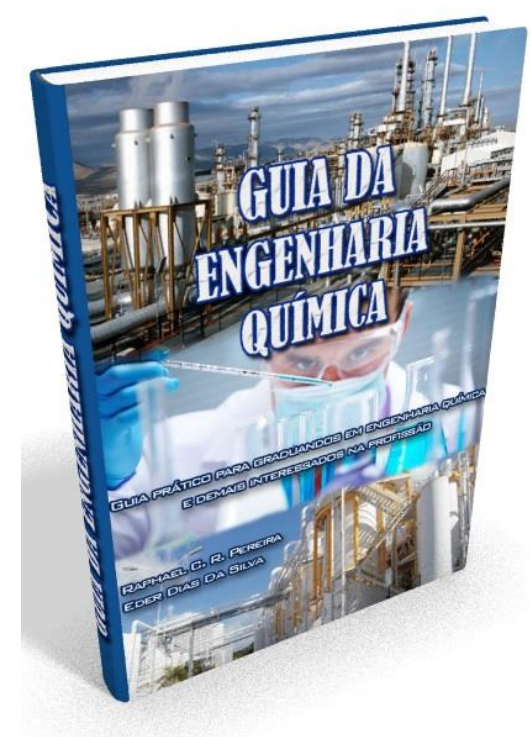

\section{CONCLUSÃO}

Em virtude dos dados coletados na primeira parte do projeto, ou seja, o questionário realizado com os alunos do curso de Engenharia Química do UNIPAM foi possível analisar o quanto os participantes ainda se sentem insatisfeitos com a forma com que o curso os apresenta informações sobre o mercado de trabalho.

Tendo em vista que o engenheiro químico deve ser empreendedor, hábil para resolução de problemas, trabalhar em equipe e tomar iniciativas, atualizar-se às novas tecnologias e ser cada vez mais multifuncional, a confecção de um guia prático e didático que lhes acrescente informações valiosas a respeito das perspectivas do mercado e as exigências das empresas do mundo globalizado da sociedade da informação seria de grande ajuda para aumento significativo do interesse pela profissão, além de aumentar os níveis da busca pela melhora e atualização constante em meio às novas tecnologias. Além disso, com um material desse porte será possível com que a amplitude de informações se converta em novas ideias a serem aplicadas na prática empreendedora, e ao aumento da busca pelo aprendizado da língua estrangeira.

No decorrer do processo de desenvolvimento do trabalho, não foi possível aplicar entrevistas com profissionais da química e engenharia química, por incompatibilidade de horários e pela dificuldade principal que foi o tempo. Dessa forma, foi realizado um questionário fechado aos profissionais mais experientes, a fim de tabular os dados e fazer um comparativo com a opinião dos alunos do curso de engenharia química. Os professores apoiaram o projeto, com justificativa de que o guia auxiliaria na formação acadêmica dos 
alunos e atuaria em conjunto com o corpo docente. A confecção do guia foi apoiada por $92 \%$ dos alunos e $87 \%$ dos professores.

Portanto, o material está disponível na plataforma online e foi apresentado aos alunos do curso, para que eles acessem ao conteúdo do guia e indiquem para os amigos e demais interessados em conhecer a profissão ou até ingressar no curso de Engenharia Química futuramente. Dessa forma o guia será de grande ajuda a quem se forma no ensino médio e deseja conhecer mais profundamente o leque de oportunidades da carreira profissional do engenheiro químico, tornando a escolha pelo curso mais consciente. Acesso ao Guia: "www.guiadaengenhariaquimica.com".

\section{REFERÊNCIAS}

BRASIL, Nilo Indio do. Introdução à Engenharia Química. 3. ed. Rio de Janeiro: Interciência, 2013. 448 p.

HILL, Manuela Magalhães; HILL, Andrew. Investigação Por Questionário. 2. ed. Lisboa: Edições Sílabo, 2012. 377 p.

MELLO, Mario Fernando et al. O Engenheiro Químico e o Mercado de Trabalho - Expectativas e Realidade. Revista da Escola de Engenharia da Uff, [niterói], v. 15, n. 2, p.187-201, 2013.

PÓVOA, J. M.; BENTO P.E.G. O Engenheiro, sua formação e o mundo do trabalho. In: CONGRESSO BRASILEIRO DE EDUCAÇÃO EM ENGENHARIA, 33., 2005, Campina Grande. Revista de Ensino de Engenharia. Campina Grande: Abenge, 2005.

WERTHEIN, Jorge. A sociedade da informação e seus desafios. Ciência da Informação, Brasília, v. 29, n. 2, p.71-77, maio/ago. 2000.

ZANGIROLAMI, Teresa C. et al. Formação do Engenheiro Químico Globalizado: Aplicação do Projeto Mirror na Comparação de Cursos de Engenharia Química de Diferentes Países. In: CONGRESSO BRASILEIRO DE EDUCAÇÃO EM ENGENHARIA, 37., 2009, Recife. Revista de Ensino de Engenharia. Recife: Abenge, 2009. 